\title{
Development of a highly sensitive and reliable enzyme-linked immunosorbent assay for MUC5AC in human tears extracted from Schirmer strips
}

This article was published in the following Dove Press journal: Clinical Ophthalmology

\author{
Hideki Miyake \\ Naoto Mori \\ Hidetoshi Mano \\ Takahiro Imanaka \\ Masatsugu Nakamura
}

Research and Development Division, Santen Pharmaceutical Co., Ltd., Osaka, Japan
Correspondence: Hideki Miyake Research and Development Division, Santen Pharmaceutical Co., Ltd., 4-20 Ofuka-cho, Kita-ku, Osaka 530-8552, Japan

$\mathrm{Tel}+8 \mathrm{I} 648029384$

Fax +8I 663593846

Email hideki.miyake@santen.com
Purpose: Reliable measurement of MUC5AC in human tears is essential for elucidation of the pathophysiological role of MUC5AC in dry eye disease. The purpose of this study was to develop a sensitive and reliable method for measurement of MUC5AC in human tear samples extracted from Schirmer strips by modifying a commercially available ELISA.

Methods: MUC5AC was extracted from Schirmer strips containing human tears by PBS with various concentrations of polysorbate 20 . The extracts were treated with neuraminidase A to cleave the sialic acids in MUC5AC. An ELISA plate was blocked to prevent nonspecific binding. The rate of extraction of MUC5AC from Schirmer strips, linearity of dilution, limit of quantification, calibration range, and intra-assay and inter-assay reproducibility were examined.

Results: MUC5AC was extracted using polysorbate 20 in a concentration-dependent manner. Extraction was more efficient at $37^{\circ} \mathrm{C}$ than at $25^{\circ} \mathrm{C}$. The signal-to-noise ratio of the assay was dramatically increased by treatment with neuraminidase A. Treatment with a blocking reagent before incubation produced good linearity of dilution. The inter-assay and intra-assay coefficients of variation were $\leq 16.6 \%$. The relative error was within $13 \%$.

Conclusion: We developed an efficient method for extraction of MUC5AC from Schirmer strips and a highly sensitive, reliable assay for MUC5AC in human tear samples using a commercially available ELISA kit. This method will aid in our understanding of the pathophysiology of dry eye, assessment of the effects of treatment in daily practice, and selection of appropriate therapeutic agents for patients.

Keywords: mucin, MUC5AC, Schirmer test, dry eye, tears, assay

\section{Introduction}

Dry eye has recently been defined by the Asia Dry Eye Society as "[...] a multifactorial disease characterized by unstable tear film causing a variety of symptoms and/or visual impairment, potentially accompanied by ocular surface damage". ${ }^{1}$ The Tear Film \& Ocular Surface Society has also commented on the multifactorial nature of dry eye, describing it as a disease in which loss of homeostasis of tear film is the central pathophysiological concept. ${ }^{2}$ These definitions recognize that unstable tear film is the pivotal mechanism causing symptoms and/or visual impairment in patients with dry eye. Tear film consists of lipid, aqueous, and mucin layers. When an abnormality develops in one of these three layers, the tear film becomes unstable, potentially leading to development of dry eye. Clarifying the causes of dry eye would enable correct treatment to be chosen for individual patients. Recent advances in diagnostic 
technology have greatly improved our ability to characterize the various subtypes of dry eye. According to the concept of tear film-oriented therapy, dry eye should also be classified according to the type of deficiency in tear components. ${ }^{1}$

Heavy glycosylation of mucins is believed to impart a highly negative charge, and a hydrophilicity that provides a barrier to adherence of pathogens and their penetration into the epithelium as well as a lubricating surface that prevents epithelial-epithelial friction during blinking. ${ }^{3}$ There are subtypes of mucins at the ocular surface, ${ }^{3}$ including gel-forming MUC5AC expressed by goblet cells in the conjunctiva. ${ }^{4}$ One of the characteristic signs of dry eye is loss of goblet cells..$^{5,6}$ Expression of MUC5AC in impression cytology specimens was found to be lower in patients with severe symptoms of dry eye than in those with mild to moderate symptoms. ${ }^{7}$ Furthermore, it has been reported that the mean MUC5AC concentration is comparatively low in the tears of visual display terminal users with dry eye. ${ }^{8}$ Therefore, the decrease in MUC5AC concentration may impair the wettability of the epithelium on the ocular surface.

Several mucin assay methods have been developed for detection of markers in biological specimens from the ocular surface in humans. Sialic acid in human tear samples is considered to be an appropriate substitute marker for monitoring of mucin levels in dry eye, ${ }^{9}$ and for investigating the efficacy of diquafosol tetrasodium, a mucin secretagogue. ${ }^{10}$ However, this method cannot detect the mucin subtype because sialic acid is only a general mucin marker. The major advantage of using an immunoassay is that a specific antibody can be used to quantify the amount of a single mucin species..$^{5,8,11}$ An immunoassay method for detecting MUC5AC on Schirmer strips has been established. ${ }^{11}$ Using this method, Schirmer strips are incubated with a polyclonal antibody and images of the strips are analyzed by scanning densitometry. However, this methodology has several limitations, including low sensitivity and low throughput as well as assays not being able to be duplicated.

A commercially available MUC5AC ELISA kit that uses flushed tear samples has recently been described. ${ }^{8}$ Although this method has clarified the pathophysiological role of MUC5AC in patients, to the best of our knowledge, the accuracy and sensitivity of this kit has not been validated for detection of MUC5AC in human tears. Furthermore, flushed tear samples are not easy to collect in multicenter clinical trials or in daily practice because of the need for training of investigators and special instruments. However, the Schirmer strip test is often used in the diagnosis of ocular surface diseases, particularly dry eye, and is a less invasive test that is acceptable to patients.
The purpose of this study was to develop a suitable method for extraction of MUC5AC from Schirmer strips containing human tears, and a highly sensitive and reliable assay method for MUC5AC by modifying the measurement technique using a commercially available ELISA kit. Precise detection of MUC5AC levels in tears would allow clinicians to not only diagnose dry eye, but also assess the effects of treatment in clinical trials and in daily practice.

\section{Materials and methods Study materials}

Approval to use human tears in this study was granted by the Ethical Review Board at Santen Pharmaceutical Co., Ltd. The ELISA kit for human MUC5AC (SEA756Hu) was sourced from Cloud-Clone Corp. (Houston, TX, USA) and the Schirmer strips were purchased from Ayumi Pharmaceutical Corporation (Tokyo, Japan). Pooled human tears (lots T5631 and T5701) were purchased from Lee Biosolutions, Inc., (Maryland Heights, MO, USA). Dulbecco's Phosphate buffered saline (PBS) (-) was obtained from Wako Pure Chemical Industries, Ltd. (Osaka, Japan) and polysorbate 20 from Wako Pure Chemical Industries, Ltd. or Sigma-Aldrich Co. (St Louis, MO, USA). $\alpha 2-3,6,8,9$ neuraminidase A (20,000 U/mL) was purchased from New England Biolabs Japan Inc. (Tokyo, Japan). Block Ace Powder was purchased from DS Pharma Biomedical Co., Ltd. (Osaka, Japan). The BCA protein assay kit used was obtained from Thermo Fisher Scientific (Waltham, MA, USA). Water was obtained from a Milli-Q water purification system (Merck KGaA, Darmstadt, Germany). The extraction solution was prepared by mixing Dulbecco's PBS (-) and polysorbate 20.

\section{Measurement of MUC5AC concentration by ELISA}

ELISA was performed according to the manufacturer's instructions unless otherwise indicated. The standard human MUC5AC is recombinant peptide Tyr5568-His5654 derived from an Escherichia coli expression system. The capture and detection monoclonal antibodies are developed using the human MUC5AC peptide. All the antibodies and standard peptide were purified by Cloud-Clone Corp. The OD at $450 \mathrm{~nm}$ was measured using a microplate reader (Spectra MAX 384; Molecular Devices LLC, Sunnyvale, CA, USA or Infinite M400; Tecan Japan Co., Ltd., Tokyo, Japan).

\section{Extraction of MUC5AC and total protein from tears in Schirmer strips}

Each Schirmer strip was spotted with $10 \mu \mathrm{L}$ of pooled human tears (lot T5701) and placed in a cryotube. After addition of 
$600 \mu \mathrm{L}$ of extraction solution with or without $0.05 \%, 0.2 \%$, or $0.5 \%$ polysorbate 20 to the cryotube, the tube was shaken for 1 hour at $25^{\circ} \mathrm{C}$ or $37^{\circ} \mathrm{C}$ to prepare samples for recovery. As a reference sample, $10 \mu \mathrm{L}$ of pooled human tears were mixed with $600 \mu \mathrm{L}$ of extraction solution corresponding to that of the recovery sample. The extraction rate was calculated as the (measured concentration of recovery sample)/(measured concentration of reference sample) $\times 100$.

\section{Effects of polysorbate 20 on OD values of MUC5AC ELISA for human tear samples}

Ten microliters of pooled human tears (lot T5701) were mixed with $600 \mu \mathrm{L}$ of extraction solution containing $0.05 \%$, $0.2 \%$, or $0.5 \%$ polysorbate 20 and applied to the MUC5AC ELISA plate following the manufacturer's instructions. The OD values of each sample were recorded.

\section{Effect of treating MUC5AC with neuraminidase $A$}

Mucin-antibody binding was considered difficult because mucin is covered with a heavy glycosylated chain. Therefore, we assessed the ability of neuraminidase A to cleave this glycosylated chain and increase the sensitivity of the ELISA kit for MUC5AC. First, $\alpha 2-3,6,8,9$ neuraminidase A $(20,000 \mathrm{U} / \mathrm{mL})$ was added to tubes containing a mixture of $300 \mu \mathrm{L}$ of extraction solution and $5 \mu \mathrm{L}$ of pooled human tears (lot T5701) at final concentrations of 0,65 , and $635 \mathrm{U} / \mathrm{mL}$, followed by incubation for 0,1 , and 2 hours at $37^{\circ} \mathrm{C}$. One hundred microliters of the mixture including neuraminidase A was then added to each well of the ELISA plate and incubated for 2 hours at $37^{\circ} \mathrm{C}$ under shaking, according to the manufacturer's instructions. Two hundred and twenty microliters of the extraction solution, $10 \mu \mathrm{L}$ of pooled human tears (lots T5631 and T5701), and $\alpha 2-3,6,8,9$ neuraminidase A (final concentration $83 \mathrm{U} / \mathrm{mL}$ ) were mixed in a tube for evaluation of the signal-to-noise $(\mathrm{S} / \mathrm{N})$ ratio and the reproducibility of the different tear lots. The mixture was then applied to the ELISA plate following the instructions in the MUC5AC kit manual. The $\mathrm{S} / \mathrm{N}$ ratio was calculated as the (sample OD value)/(extraction solution OD value).

\section{Blocking of ELISA plate and linearity of dilution}

A preliminary study showed that the relationship between the MUC5AC concentration in tear samples and the dilution rate was not linear (data not shown), so it was assumed that the binding of MUC5AC with the ELISA plate was nonspecific. Therefore, we determined whether blocking of the ELISA plate could suppress nonspecific binding. First, a stock solution of block ace was prepared by dissolving $40 \mathrm{~g}$ of Block Ace Powder in $100 \mathrm{~mL}$ of water. The stock block ace solution was then diluted four times with water to prepare the blocking reagent. Next, 300 $\mu \mathrm{L}$ of the blocking reagent was added to the ELISA plate, which was then incubated for 30 minutes at $25^{\circ} \mathrm{C}$ followed by removal of the liquid from each well for measurement of MUC5AC. After preparing a diluted tear sample with the extraction solution, the linearity of MUC5AC dilution was examined (singlicate measurements were taken at each concentration). Two lots (T5631 and T5701) of pooled human tears were investigated for linearity of dilution using the following procedure. The pooled tears were serially diluted with extraction solution; 60 -fold to 480 -fold dilutions were used for samples with blocking of the ELISA plate and 60-fold to 1,080-fold dilutions were used for samples without blocking of the ELISA plate. The MUC5AC concentration was determined from the OD value using the calibration curve. The converted values were calculated from the interpolated concentrations at each dilution multiplied by the corresponding dilution factors. The dilution ratio was calculated as the (concentration at the corresponding dilution $) \times($ dilution factor $) /($ concentration at 60 -fold). When the dilution ratio is close to 1 , the linearity is good.

\section{Protein assay}

Protein in extracts from the Schirmer strip was measured using the BCA protein assay kit. The assay was performed according to the manufacturer's instructions.

\section{Calibration curve for MUC5AC}

The standard human MUC5AC recombinant peptide is derived from an E. coli expression system and was provided by Cloud-Clone Corp. The standard stock solution of MUC5AC peptide was diluted with extraction solution, and eight calibration standard samples containing MUC5AC peptide at concentrations of $0,19.5,39.1,78.1,156.3,312.5$, 625 , and $1,250 \mathrm{pg} / \mathrm{mL}$ were prepared. These samples were analyzed (in duplicate, $\mathrm{n}=1$ ) on two separate days.

\section{Intra-assay and inter-assay precision and accuracy, lower limit of quantification}

The intra-assay and inter-assay precision and accuracy were evaluated to confirm the robustness of our method. Quality control (QC) samples containing MUC5AC at concentrations of $39.1,100,1,000$, and $1,250 \mathrm{pg} / \mathrm{mL}$ were prepared by diluting the standard stock solution with extraction solution. 
The intra-day precision and accuracy were determined by analyzing five sets of QC samples at four concentration levels on each day. The inter-day precision and accuracy were determined by analyzing five sets of QC samples at four concentration levels over 3 consecutive days. The lower limit of quantification, set as the minimum concentration that met the acceptance criteria (described in the following paragraph), was determined by analyzing the previously mentioned QC samples.

\section{Acceptance criteria}

Accuracy and precision are reported as the relative error (RE) and coefficient of variation (CV). The RE value was set within $20 \%$ as the accuracy criterion and a $\% \mathrm{CV}$ less than $20 \%$ as the precision criterion according to the criteria described in the US Food and Drug Administration guidelines. ${ }^{12}$

\section{Results}

\section{Extraction of MUC5AC and total protein in tears from Schirmer strips}

Figure 1 shows the rate of extraction of MUC5AC from the Schirmer strips. For the sample extracted with $600 \mu \mathrm{L}$ of PBS without polysorbate at $25^{\circ} \mathrm{C}$, the extraction rate was $24 \%$, even though the total amount of protein extracted was $68 \%$. The extraction rate increased with increasing concentrations of polysorbate 20 . PBS with $0.05 \%$ polysorbate 20 at $25^{\circ} \mathrm{C}$ extracted $77 \%$ of MUC5AC and $85 \%$ of total protein. The extraction rate at $37^{\circ} \mathrm{C}$ was $89 \%$ for MUC5AC and $86 \%$ for total protein; both these values are higher than those recorded at $25^{\circ} \mathrm{C}$.

\section{Effects of polysorbate 20 on OD values in MUC5AC ELISA for human tear samples}

Table 1 shows the effects of polysorbate 20 on the OD values. The data indicate that the OD values reach a peak at $0.05 \%$ and then decrease in a concentration-dependent manner. Although a higher extraction rate was achieved using PBS containing more polysorbate 20 (Figure 1), over $0.2 \%$ of polysorbate 20 reduced the OD value in ELISA.

\section{Effect of neuraminidase A on MUC5AC concentration}

First, we optimized the neuraminidase A concentration and incubation time (Figure 2). The MUC5AC concentration was dramatically increased by treatment with neuraminidase A. The concentration $>65 \mathrm{U} / \mathrm{mL}$ and 2 hours of reaction time were identified as optimal conditions. To evaluate the $\mathrm{S} / \mathrm{N}$ ratio and reproducibility of the different tear lots, we conducted ELISA for two tear lots at the incubation step with and without neuraminidase $\mathrm{A}$ (Table 2). When the pooled human tear samples were treated with neuraminidase A for 2 hours at $37^{\circ} \mathrm{C}$ during the ELISA assay, there was a dramatic increase in the $\mathrm{S} / \mathrm{N}$ ratio by more than 8 -fold when compared with the samples that were not treated with the enzyme (Table 2).

\section{Blocking of the ELISA plate and linearity of dilution}

In this study, each pooled human tear sample was serially diluted with extraction solution; 60 -fold to 480 -fold dilutions were applied in the sample with blocking of ELISA plate and 60-fold to 1,080-fold dilutions were applied in the sample

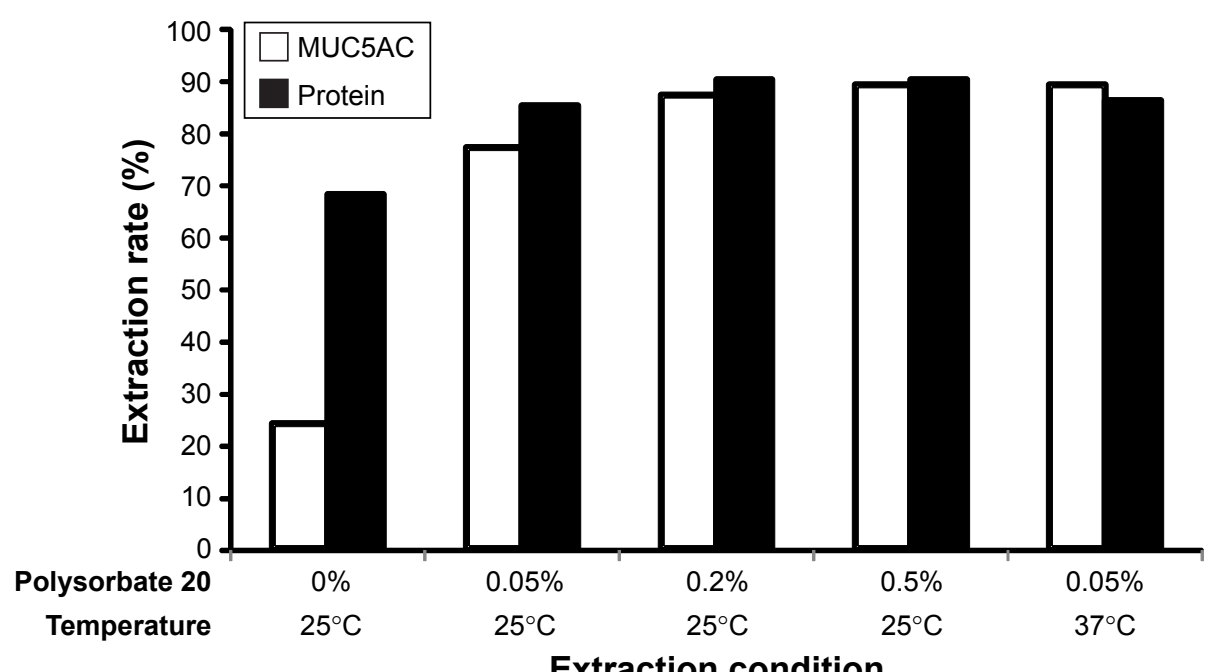

Figure I Rates of extraction of MUC5AC and total protein in human tears from Schirmer strips.

Notes: Human tears were extracted from Schirmer strips using $600 \mu \mathrm{L}$ of extraction solution for I hour. The graph shows the average of duplicate assays. The white ( $\square$ ) and black ( $\square)$ columns show the extraction rates for MUC5AC and total protein, respectively. 
Table I Effects of polysorbate 20 on the OD values in a MUC5AC ELISA for human tear samples

\begin{tabular}{|c|c|c|c|c|}
\hline \multirow[t]{2}{*}{ OD value } & \multicolumn{4}{|c|}{ Polysorbate 20 concentration } \\
\hline & $0 \%$ & $0.05 \%$ & $0.2 \%$ & $0.5 \%$ \\
\hline & 0.945 & 1.052 & 0.963 & 0.865 \\
\hline & 0.925 & 1.035 & 0.963 & 0.892 \\
\hline Mean & 0.935 & 1.044 & 0.963 & 0.879 \\
\hline
\end{tabular}

Note: Ten microliters of pooled human tears and $600 \mu \mathrm{L}$ of extraction solution with $0 \%, 0.05 \%, 0.2 \%$, and $0.5 \%$ polysorbate 20 were mixed followed by measurement of MUC5AC.

without blocking of the ELISA plate. Table 3 and Figure 3 show the linearity of dilution with and without blocking treatment. The sample without blocking did not show the MUC5AC concentration in response to dilution, even when diluted up to 1,080-fold. When the ELISA plate was treated with stock block ace solution or block ace solution that was diluted 4-fold for 30 minutes before the sample incubation step, the respective dilution ratios were 1.00-2.19 and $0.63-1.00$. In the absence of blocking, the dilution ratio was 1.0-8.4. When the dilution ratio is close to 1 , linearity is good. Therefore, these results indicated that blocking of the ELISA plate improved the linearity of dilution within the range of 60-480-fold, so the blocking step was added to the MUC5AC ELISA procedure. However, the detection sensitivity in the tear sample was markedly decreased after treatment with the stock block ace solution when compared with that after treatment with the 4-fold diluted solution.

\section{Calibration curve for MUC5AC}

Table 4 shows the calibration curves fitted to a four-parameter model. We prepared eight standard calibration samples containing MUC5AC at concentrations of 0, 19.5, 39.1, 78.1,
$156.3,312.5,625$, and $1,250 \mathrm{pg} / \mathrm{mL}$. When $19.5 \mathrm{pg} / \mathrm{mL}$ of MUC5AC was set as the anchor point, the accuracy (RE) in the range of $39.1-1,250 \mathrm{pg} / \mathrm{mL}$ was $-10.5 \%$ to $13.0 \%$, which met the acceptance criteria. The optimal range was determined to be $39.1-1,250 \mathrm{pg} / \mathrm{mL}$.

\section{Intra-assay and inter-assay precision and accuracy, lower limit of quantification}

Table 5 shows the intra-assay and inter-assay accuracy and precision of the MUC5AC ELISA kit. Precision and accuracy were determined by analysis of QC samples at 39.1, 100, 1,000 , and $1,250 \mathrm{pg} / \mathrm{mL}$. The intra-assay precision (CV) and accuracy (RE) were in the ranges of $2.6 \%$ to $16.6 \%$ and $-13.0 \%$ to $5.3 \%$, respectively, and met the acceptance criteria. The inter-assay CV and RE of $6.4 \%$ to $10.8 \%$ and $-8.5 \%$ to $-1.5 \%$, respectively, over 3 days also met the acceptance criteria. Therefore, we set the lower limit of quantification at $39.1 \mathrm{pg} / \mathrm{mL}$.

\section{Discussion}

A quantitative change in the components in tears on the ocular surface can lead to abnormal ocular surface conditions, such as an abnormal tear film layer. Although mucin deficiency cannot be evaluated easily in daily clinical practice, dry eye with a short tear break-up time is probably the most common type of dry eye associated with mucin deficiency. Therefore, exploration and development of monitoring methods such as biomarkers is important. ${ }^{1,13}$ Inclusion of minimally invasive objective metrics, such as tear component profiles that include MUC5AC, will aid not only in understanding changes on the ocular surface but also in determining the effectiveness of new treatments.

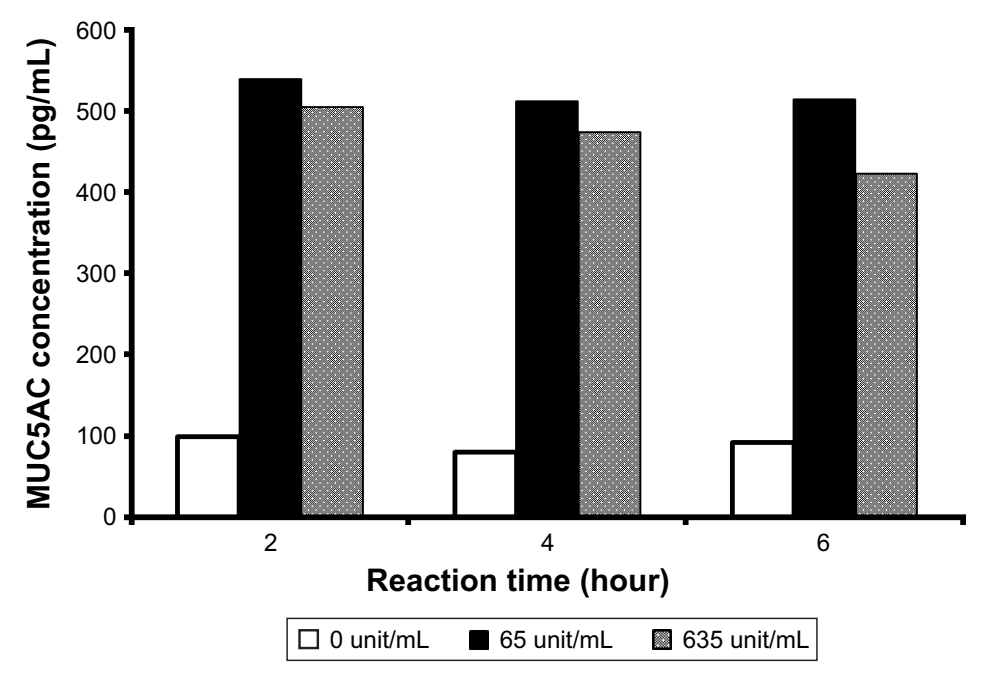

Figure 2 Effects of neuraminidase A concentration and reaction time on MUC5AC concentration in pooled human tear samples. Note: The enzyme was incubated for $0, \mathrm{I}$, and 2 hours in each tube and each well of an ELISA plate for 2 hours at $37^{\circ} \mathrm{C}$. 
Table 2 Change in the signal/noise $(\mathrm{S} / \mathrm{N})$ ratio of absorbance with and without neuraminidase $A$ treatment

\begin{tabular}{|c|c|c|c|c|c|c|}
\hline \multirow{2}{*}{$\begin{array}{l}\text { Tear lot } \\
\text { No. }\end{array}$} & \multicolumn{3}{|l|}{ T563I } & \multicolumn{3}{|l|}{ T570I } \\
\hline & $\begin{array}{l}\text { OD } \\
\text { value }\end{array}$ & $\begin{array}{l}\text { Mean } \\
\text { OD value }\end{array}$ & $\begin{array}{l}\mathrm{S} / \mathrm{N} \\
\text { ratio }\end{array}$ & $\begin{array}{l}\text { OD } \\
\text { value }\end{array}$ & $\begin{array}{l}\text { Mean } \\
\text { OD value }\end{array}$ & $\begin{array}{l}\mathbf{S} / \mathbf{N} \\
\text { ratio }\end{array}$ \\
\hline & 0.4466 & 0.41255 & 1.13 & 0.3100 & 0.30485 & 0.83 \\
\hline neuraminidase & 0.3785 & & & 0.2997 & & \\
\hline With & 3.4253 & 3.50375 & 9.57 & 3.4652 & 3.36465 & 9.19 \\
\hline neuraminidase & 3.5822 & & & $3.264 I$ & & \\
\hline
\end{tabular}

Notes: The S/N ratio was calculated as the (sample OD value)/(extraction solution OD value). The extraction solution OD value was 0.3663 .

Although some MUC5AC protein assay methods have been reported in clinical research, ${ }^{5,8,11}$ no MUC5AC assay has been used in daily practice or in multicenter clinical trials. Improvements in the assay method and establishment of procedures, including collection of tear samples, will allow more reproducible and reliable measurement of MUC5AC at the ocular surface. In this study, we developed a highly sensitive and reliable MUC5AC assay that included a sample extraction step.

Tear samples, especially those obtained from individuals with dry eye, are likely to be small and of insufficient volume to allow assays to be repeated, so an efficient method for collection of tear samples and a highly sensitive assay method are essential. The Schirmer test is widely used to measure tear volume in multicenter clinical trials because it is easy to apply and does not require special equipment. ${ }^{14,15}$ This test can also be used to collect tear samples ${ }^{16}$ for analysis of cytokines,${ }^{17}$ nucleic acids, ${ }^{18}$ and immunoglobulin. ${ }^{19}$

It was recently reported that use of Schirmer strips was better for collection of MUC5AC than basal or flushed tear collection. ${ }^{20}$ However, there have been no reports on the efficiency of extraction of MUC5AC from a Schirmer strip. Our data show that extraction of MUC5AC by PBS alone is limited even though total protein is recovered efficiently. Recovery of both MUC5AC and total protein in the extraction solution increased with increasing polysorbate 20 content and with high reproducibility. Polysorbate 20 is widely used as a washing solution in ELISA kits because it is considered to be a non-denaturing detergent and to have little effect on the assay system. We found that addition of a low concentration of polysorbate 20 solution to the ELISA plate improved the detection of sensitivity. We presume that reduced proteinprotein interaction and/or the viscosity of the tear samples are responsible for this increase in sensitivity. Furthermore, when the concentration of polysorbate 20 in the ELISA assay was higher than $0.05 \%$, the extraction efficiency of MUC5AC improved but the OD decreased. A higher concentration of detergent is thought to inhibit the MUC5AC-antibody reaction. Extraction at $37^{\circ} \mathrm{C}$ was more efficient than at $25^{\circ} \mathrm{C}$. In summary, protein including MUC5AC in the tear samples was recovered by extraction solution containing $0.05 \%$ polysorbate 20 at $37^{\circ} \mathrm{C}$ for 1 hour.

MUC5AC is assumed to be present at a very low concentration in human tears, so we attempted to increase the sensitivity of the ELISA assay by cleaving sialic acids from MUC5AC using neuraminidase A. Treatment with neuraminidase A dramatically improved the $\mathrm{S} / \mathrm{N}$ ratio and had higher sensitivity at a low concentration level. It is difficult for the antibody to bind to the core peptide of mucin because it is covered by a heavy glycosylated chain. Neuraminidase A cleaves sialic acids from heavily sialylated glycoproteins.

Table 3 Assessment of linearity of dilution with and without blocking treatment

\begin{tabular}{|c|c|c|c|c|c|c|c|c|c|c|}
\hline \multirow{2}{*}{$\begin{array}{l}\text { Tear lot } \\
\text { No. }\end{array}$} & \multicolumn{5}{|l|}{ T563I } & \multicolumn{5}{|l|}{ T570I } \\
\hline & $\begin{array}{l}\text { OD } \\
\text { value }\end{array}$ & $\begin{array}{l}\text { Concentration } \\
(\mathrm{pg} / \mathrm{mL})\end{array}$ & $\begin{array}{l}\text { Dilution } \\
\text { factor }\end{array}$ & $\begin{array}{l}\text { Converted } \\
\text { value }(\mathrm{pg} / \mathrm{mL})\end{array}$ & $\begin{array}{l}\text { Dilution } \\
\text { ratio }\end{array}$ & $\begin{array}{l}\text { OD } \\
\text { value }\end{array}$ & $\begin{array}{l}\text { Concentration } \\
(\mathrm{pg} / \mathrm{mL})\end{array}$ & $\begin{array}{l}\text { Dilution } \\
\text { factor }\end{array}$ & $\begin{array}{l}\text { Converted } \\
\text { value }(\mathrm{pg} / \mathrm{mL})\end{array}$ & $\begin{array}{l}\text { Dilution } \\
\text { ratio }\end{array}$ \\
\hline Without & 2.3327 & I,330.7 & 60 & $79,843.0$ & 1.00 & 2.3403 & I,334.7 & 60 & $80,081.6$ & 1.00 \\
\hline \multirow[t]{3}{*}{ blocking } & 2.4078 & $1,369.6$ & 120 & $164,353.0$ & 2.06 & 2.4813 & I,406.8 & 120 & $168,8 \mid 9.7$ & 2.11 \\
\hline & 2.2832 & $1,304.6$ & 360 & $469,657.5$ & 5.88 & 1.7355 & 990.0 & 360 & $356,389.3$ & 4.45 \\
\hline & 1.1715 & 621.2 & 1,080 & $670,849.3$ & 8.40 & 0.9120 & 442.7 & $\mathrm{I}, 080$ & $478,158.1$ & 5.97 \\
\hline With block & 0.4959 & 135.0 & 60 & $8,102.6$ & 1.00 & 0.3076 & 70.7 & 60 & $4,242.2$ & 1.00 \\
\hline \multirow[t]{3}{*}{ ace $\times 1$} & 0.2801 & 61.9 & 120 & $7,429.5$ & 0.92 & 0.1888 & 34.5 & 120 & $4,14 \mid .8$ & 0.98 \\
\hline & 0.2124 & 41.3 & 240 & $9,904.4$ & 1.22 & 0.1405 & 21.9 & 240 & $5,259.9$ & 1.24 \\
\hline & 0.1819 & 32.6 & 480 & I5,647.4 & 1.93 & 0.1291 & 19.4 & 480 & $9,309.6$ & 2.19 \\
\hline With block & 2.2888 & 853.4 & 60 & $5 I, 206.1$ & 1.00 & 1.4304 & 467.9 & 60 & $28,07 I .1$ & 1.00 \\
\hline \multirow[t]{3}{*}{ ace $\times 4$} & 1.2207 & 380.5 & 120 & $45,657.4$ & 0.89 & 0.6076 & | 47.8 & 120 & $|7,738|$. & 0.63 \\
\hline & 0.6024 & 146.0 & 240 & $35,049.2$ & 0.68 & 0.4528 & 96.9 & 240 & $23,256.3$ & 0.83 \\
\hline & 0.3956 & 79.3 & 480 & $38,087.8$ & 0.74 & 0.2938 & 50.4 & 480 & $24,2 \mid 4.7$ & 0.86 \\
\hline
\end{tabular}

Notes: The MUC5AC concentration was determined from the OD value using the calibration curve within the same analysis run. The converted value was calculated as the (concentration at corresponding dilution) $\times$ (dilution factor) and the dilution ratio as the (converted value)/(converted value at 60 -fold). When the dilution ratio is close to I, the linearity is good. Block ace $\times 1$, stock block ace solution, block ace $\times 4$, block ace solution that has been diluted by 4-fold. 


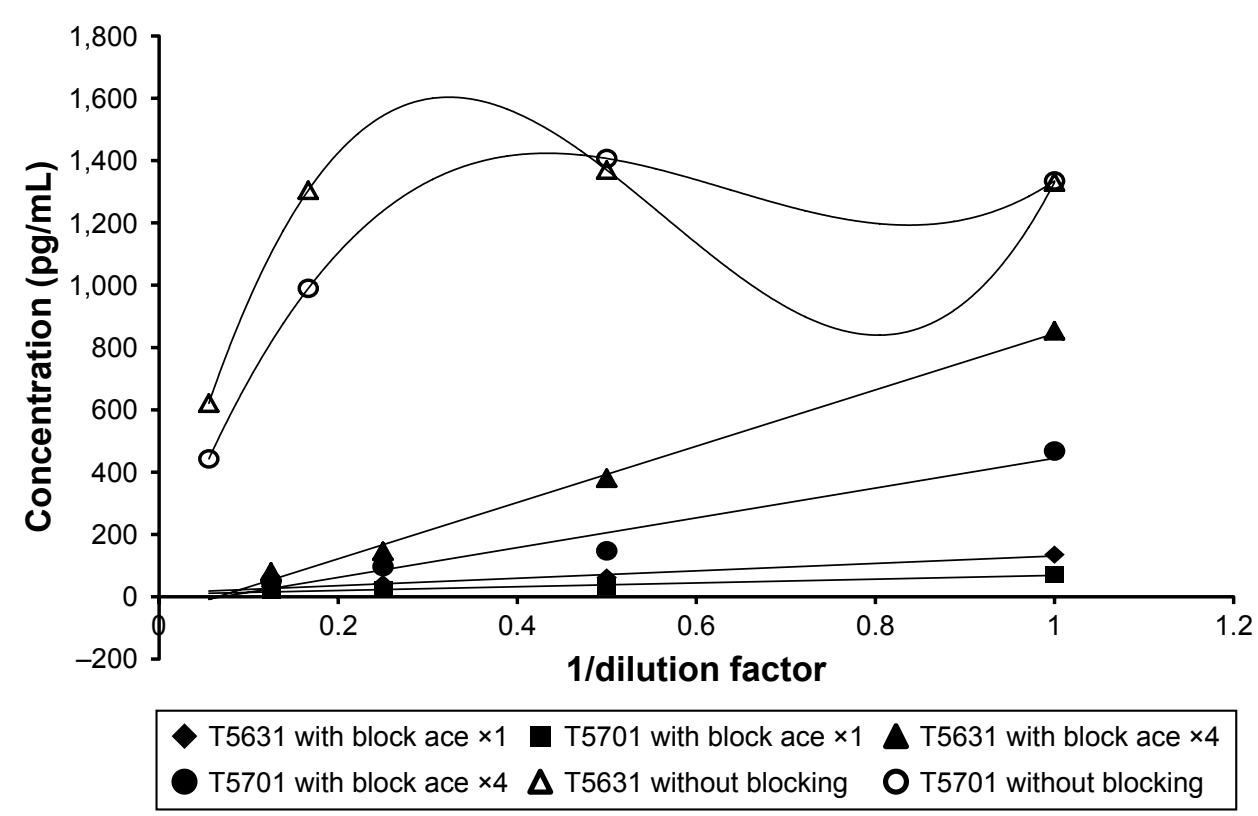

Figure 3 Assessment of linearity of dilution with and without blocking treatment.

Notes: A linear approximation line was applied to the plot with blocking. A smooth curve through each datum point was applied to the plot without blocking (singlicate, $\mathrm{n}=\mathrm{I}$ ). Block ace $\times I$, stock block ace solution, block ace $\times 4$, block ace solution that has been diluted by 4 -fold.

In our study, treatment of the tear samples with neuraminidase A facilitated access of the antibody to the mucin core protein. This finding has been reported previously for MUC5AC and other mucins. 5,21

Following the original protocol, the commercial ELISA kit did not show linearity of dilution for MUC5AC in human tear samples. This finding could be explained by a nonspecific interaction between MUC5AC and the ELISA plate. The tear sample volume differs from subject to subject, so a linearity of dilution experiment provides information about the precision of results for samples tested at different levels of dilution in a given tear diluent. Our preliminary data

Table 4 Calibration curve for the MUC5AC ELISA kit

\begin{tabular}{|c|c|c|c|c|c|c|c|c|c|}
\hline \multicolumn{5}{|l|}{ Day I } & \multicolumn{5}{|l|}{ Day 2} \\
\hline $\begin{array}{l}\text { Sample } \\
\text { (pg/mL) }\end{array}$ & $\begin{array}{l}\text { OD } \\
\text { value }\end{array}$ & $\begin{array}{l}\text { Mean } \\
\text { OD value }\end{array}$ & $\begin{array}{l}\text { Calculated } \\
\text { concentration }(\mathrm{pg} / \mathrm{mL})\end{array}$ & RE (\%) & $\begin{array}{l}\text { Sample } \\
\text { (pg/mL) }\end{array}$ & $\begin{array}{l}\text { OD } \\
\text { value }\end{array}$ & $\begin{array}{l}\text { Mean } \\
\text { OD value }\end{array}$ & $\begin{array}{l}\text { Calculated } \\
\text { concentration }(\mathrm{pg} / \mathrm{mL})\end{array}$ & RE (\%) \\
\hline \multirow[t]{2}{*}{1,250} & 2.6967 & 2.69245 & $1,246.3$ & -0.3 & 1,250 & 3.0226 & 3.04515 & I,24I.6 & -0.7 \\
\hline & 2.6882 & & & & & 3.0677 & & & \\
\hline \multirow[t]{2}{*}{625} & I.458| & I.47225 & 635.5 & 1.7 & 625 & I.8444 & 1.84630 & 652.8 & 4.4 \\
\hline & $\mathrm{I} .4864$ & & & & & I.8482 & & & \\
\hline \multirow[t]{2}{*}{312.5} & 0.7581 & 0.81935 & 312.3 & -0.1 & 312.5 & I.0084 & 1.02435 & 289.3 & -7.4 \\
\hline & 0.8806 & & & & & 1.0403 & & & \\
\hline \multirow[t]{2}{*}{156.3} & 0.4701 & 0.47225 & 142.5 & -8.8 & 156.3 & 0.6740 & 0.67590 & 151.6 & -3.0 \\
\hline & 0.4744 & & & & & 0.6778 & & & \\
\hline \multirow[t]{2}{*}{78.1} & 0.3292 & 0.32575 & 71.8 & -8.1 & 78.1 & 0.4133 & 0.44565 & 69.9 & -10.5 \\
\hline & 0.3223 & & & & & 0.4780 & & & \\
\hline \multirow[t]{2}{*}{39.1} & 0.2816 & 0.26790 & 44.2 & 13.0 & 39.1 & 0.3502 & 0.33755 & 36.0 & -8.0 \\
\hline & 0.2542 & & & & & 0.3249 & & & \\
\hline \multirow[t]{2}{*}{19.5} & 0.2240 & 0.22385 & 23.4 & 20.2 & 19.5 & 0.2948 & 0.30740 & 27.4 & 40.3 \\
\hline & 0.2237 & & & & & 0.3200 & & & \\
\hline \multirow[t]{2}{*}{9.8} & 0.1856 & 0.17970 & - & - & 9.8 & 0.2625 & 0.28725 & - & - \\
\hline & 0.1738 & & & & & 0.3120 & & & \\
\hline \multirow[t]{2}{*}{0} & 0.2072 & 0.20380 & - & - & 0 & 0.2283 & 0.23085 & - & - \\
\hline & 0.2004 & & & & & 0.2334 & & & \\
\hline
\end{tabular}

Note: The relative error (RE) values were calculated by fitting the curve to a four-parameter model in the range of $39.1-1,250 \mathrm{pg} / \mathrm{mL}$ with $19.5 \mathrm{pg} / \mathrm{mL}$ set as the anchor point. 


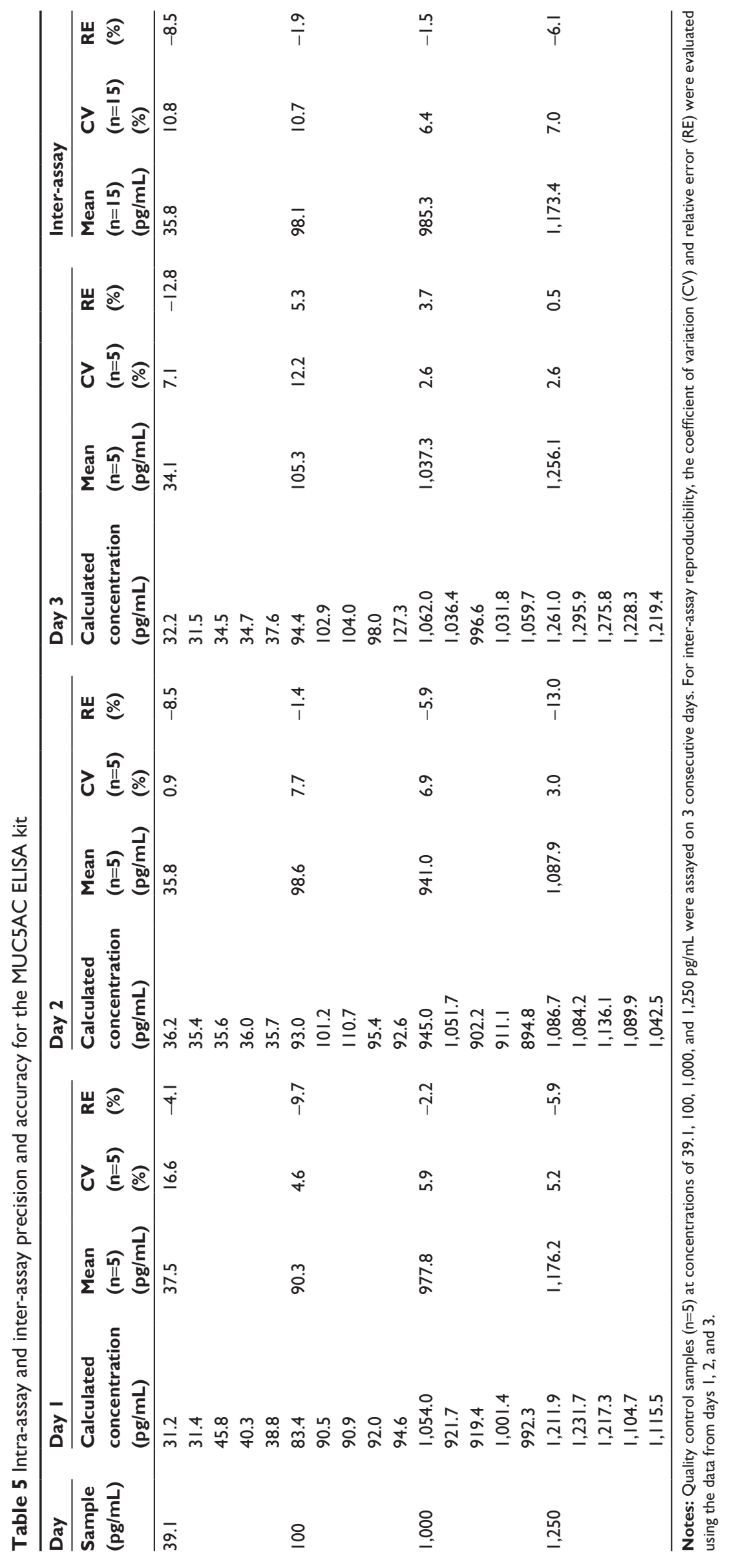


showed that casein was not an effective blocking reagent (data not shown). Adding a block ace solution to the ELISA plate improved the linearity of dilution of tear samples by reducing nonspecific adsorption and/or a matrix effect in the modified assay method. However, the stock block ace solution decreased the detection sensitivity, so we used a solution that was diluted 4-fold to achieve a good balance between detection sensitivity and linearity.

In this study, we confirmed the linearity of dilution between 60 and 480 times in the blocking condition. Assuming that tear protein can be extracted by $600 \mu \mathrm{L}$ of solution from a Schirmer strip, it would be possible to measure the MUC5AC concentration in a tear volume of $1.25 \mathrm{~mL}$ to $10 \mu \mathrm{L}$. Furthermore, the MUC5AC concentration of $39.1 \mathrm{pg} / \mathrm{mL}$ meets the criteria for accuracy and precision mentioned in the US Food and Drug Administration guideline. ${ }^{12}$ The lower limit of quantification value was improved by at least 2-fold when compared with the existing commercial ELISA kit. The intra-assay and inter-assay data also showed high accuracy and reliability. Therefore, this validated method can be considered straightforward, robust, and reproducible, and to have broad application in clinical research and daily practice. A study that includes measurement of conjunctival epithelial cells that adhere to Schirmer strips derived from human subjects should be performed as a next step.

In this study, we used the Schirmer strip manufactured by Ayumi Pharmaceutical Corporation whereas García-Porta et al analyzed the effect of five different types of Schirmer strips on protein release. ${ }^{22}$ In their study, human albumin, a negatively charged and relatively high molecular weight protein, was chosen to investigate the potential interaction between the strips and tear protein. Their results indicated that the different types of Schirmer strips varied in the pattern of albumin release, which was low in all cases. Our data demonstrated that MUC5AC, a negatively charged and high molecular weight protein, could not be extracted from the strips when using buffer without detergent. Further studies are required to determine the effects of using different types of Schirmer strips under our extraction conditions.

In conclusion, we have established and validated a method for extracting MUC5AC from Schirmer tear strips, and a highly sensitive and reliable assay method using a modified commercially available MUC5AC ELISA kit. We believe that this method will improve our understanding of the pathophysiology of dry eye. Our method could also be used to assess the effects of treatment in daily practice and to evaluate the potential of MUC5AC-secreting compounds for the treatment of dry eye disease in the clinical setting.

\section{Disclosure}

All authors are employees of Santen Pharmaceutical Co. Ltd. The authors report no other conflicts of interest in this work.

\section{References}

1. Tsubota K, Yokoi N, Shimazaki J, et al. New Perspectives on Dry Eye Definition and Diagnosis: A Consensus Report by the Asia Dry Eye Society. Ocul Surf. 2017;15(1):65-76.

2. Craig JP, Nichols KK, Akpek EK, Nichols JJ, et al. TFOS DEWS II Definition and Classification Report. Ocul Surf. 2017;15(3): 276-283.

3. Gipson IK, Hori Y, Argüeso P. Character of ocular surface mucins and their alteration in dry eye disease. Ocul Surf. 2004;2(2):131-148.

4. Jumblatt MM, Mckenzie RW, Jumblatt JE. MUC5AC mucin is a component of the human precorneal tear film. Invest Ophthalmol Vis Sci. 1999;40(1):43-49.

5. Argüeso P, Balaram M, Spurr-Michaud S, Keutmann HT, Dana MR, Gipson IK. Decreased levels of the goblet cell mucin MUC5AC in tears of patients with Sjögren syndrome. Invest Ophthalmol Vis Sci. 2002; 43(4):1004-1011.

6. Oh T, Jung Y, Chang D, Kim J, Kim H. Changes in the tear film and ocular surface after cataract surgery. Jpn J Ophthalmol. 2012;56(2): $113-118$.

7. Zhang J, Yan X, Li H. Analysis of the correlations of mucins, inflammatory markers, and clinical tests in dry eye. Cornea. 2013;32(7): 928-932.

8. Uchino Y, Uchino M, Yokoi N, et al. Alteration of tear mucin $5 \mathrm{AC}$ in office workers using visual display terminals: The Osaka Study. JAMA Ophthalmol. 2014;132(8):985-992.

9. Nakamura Y, Yokoi N, Tokushige H, Kinoshita S. Sialic Acid in human tear fluid decreases in dry eye. Jpn J Ophthalmol. 2004;48(6): 519-523.

10. Shigeyasu C, Hirano S, Akune Y, Yamada M. Diquafosol Tetrasodium Increases the Concentration of Mucin-like Substances in Tears of Healthy Human Subjects. Curr Eye Res. 2015;40(9):878-883.

11. Zhao H, Jumblatt JE, Wood TO, Jumblatt MM. Quantification of MUC5AC protein in human tears. Cornea. 2001;20(8):873-877.

12. FDA US. Guidance for Industry: Bioanalytical Method Validation. Silver Spring, MD: US Department of Health and Human Services, US FDA, Center for Drug Evaluation and Research; 2018 Available from:https://www.fda.gov/downloads/drugs/guidances/ucm070107. Pdf. Accessed July 12, 2018.

13. Willcox MDP, Argüeso P, Georgiev GA, et al. TFOS DEWS II Tear Film Report. Ocul Surf. 2017;15(3):366-403.

14. Schirmer O. Studien zur Phisiologie und Pathologie der Traenenabsonderung und Traenenabfuhr [Studies on physiology and pathology of the tear secretion and outflow]. Graefes Arch Klin Exp Ophthalmol. 1903;56:197-291. German.

15. Miyake H, Kawano Y, Tanaka H, Iwata A, Imanaka T, Nakamura M. Tear volume estimation using a modified Schirmer test: a randomized, multicenter, double-blind trial comparing 3\% diquafosol ophthalmic solution and artificial tears in dry eye patients. Clin Ophthalmol. 2016; 10:879-886.

16. Denisin AK, Karns K, Herr AE. Post-collection processing of Schirmer strip-collected human tear fluid impacts protein content. Analyst. 2012; 137(21):5088-5096.

17. Vandermeid KR, Su SP, Ward KW, Zhang JZ. Correlation of tear inflammatory cytokines and matrix metalloproteinases with four dry eye diagnostic tests. Invest Ophthalmol Vis Sci. 2012;53(3):1512-1518.

18. Pintor J, Carracedo G, Alonso MC, Bautista A, Peral A. Presence of diadenosine polyphosphates in human tears. Pflugers Arch. 2002; 443(3):432-436

19. Stuchell RN, Feldman JJ, Farris RL, Mandel ID. The effect of collection technique on tear composition. Invest Ophthalmol Vis Sci. 1984; 25(3):374-377. 
20. Ablamowicz AF, Nichols JJ. Concentrations of MUC16 and MUC5AC using three tear collection methods. Mol Vis. 2017;23:529-537.

21. Burchell J, Taylor-Papadimitriou J. Effect of modification of carbohydrate side chains on the reactivity of antibodies with core-protein epitopes of the MUC1 gene product. Epithelial Cell Biol. 1993;2(4): $155-162$.
22. García-Porta N, Mann A, Sáez-Martínez V, Franklin V, Wolffsohn JS, Tighe B. The potential influence of Schirmer strip variables on dry eye disease characterisation, and on tear collection and analysis. Cont Lens Anterior Eye. 2018;41(1):47-53.

\section{Publish your work in this journal}

Clinical Ophthalmology is an international, peer-reviewed journal covering all subspecialties within ophthalmology. Key topics include: Optometry; Visual science; Pharmacology and drug therapy in eye diseases; Basic Sciences; Primary and Secondary eye care; Patient Safety and Quality of Care Improvements. This journal is indexed on

\section{Dovepress}

PubMed Central and CAS, and is the official journal of The Society of Clinical Ophthalmology (SCO). The manuscript management system is completely online and includes a very quick and fair peer-review system, which is all easy to use. Visit http://www.dovepress.com/ testimonials.php to read real quotes from published authors. 